RTW rate varied significantly by cancer type. Of workers who returned to work after their first episode of leave after cancer, more than $50 \%$ continued to work after 5 years in largescaled companies. There was a steep decrease in work continuance rates during the first year after RTW, with considerable differences according to cancer site.

Discussion It is very important for companies (especially smalland medium-sized companies) to establish and improve their RTW support system for employees with cancer.

\section{INVESTING IN WORK ABILITY OF PATIENTS WITH IBD: RESULTS OF A PILOT PROJECT ACTIV84WORK (ACTIVATE FOR WORK)}

${ }^{1} \mathrm{M}-\mathrm{N}$ Schmickler, ${ }^{2} \mathrm{~S}$ Coenen, ${ }^{3} \mathrm{D}$ Staes, ${ }^{3} \mathrm{~F}$ Wieme, ${ }^{4} \mathrm{~T}$ Swinnen, ${ }^{5} \mathrm{X}$ Dekeuleneer, ${ }^{6} \mathrm{~T}$ van Hooland, ${ }^{7} \mathrm{~K}$ van den Cruys, ${ }^{2} \mathrm{~S}$ Vermeire. ${ }^{1}$ Mensura Occupational Health Services, Belgium; ${ }^{2}$ Translational Research Centre for Gastrointestinal Disorders, Catholic University of Leuven, Belgium; ${ }^{3}$ Crohn's and Ulcerative Colitis Association, Belgium; ${ }^{4}$ SD Worx, Global Payroll and HR Service Provider, Belgium; ${ }^{5}$ Proximus, Telecommunications Service Provider, Belgium; ${ }^{6}$ Abbvie, Biopharmaceutical research and development, Belgium; ${ }^{7}$ Novellas Healthcare, International Healthcare Recruitment, Belgium

\subsection{6/oemed-2018-ICOHabstracts. 1549}

Introduction Symptoms of inflammatory bowel disease (IBD) (e.g., diarrhoea, urgency, incontinence, and/or fatigue) often make it difficult to actively participate in the workplace and commute to and from work, especially during flare-up periods. Activ84worK was a pilot project to stimulate professional activity and reduce absenteeism in IBD patients by providing them with more flexible working conditions, including teleworking.

Methods Starting in April 2015, IBD patients were recruited for participation by a patient association and the gastroenterology department at University Hospital Leuven. Interested patients were contacted for screening and follow-up throughout the program. Both employees and their employers were followed over a six-month period. The first and last contacts were face-to-face meetings with employees and employers. Five intermediate contacts with employees were conducted by phone or email. The project was evaluated from three perspectives: benefits of teleworking for the employee, benefits for the employer, and the effect on society by measuring absenteeism.

Results Between April 2015 and October 2016, 71 patients showed interest, 19 were eligible to participate, and 14 completed the program. All patients expressed their enthusiasm for teleworking and other tailored and flexible working conditions. Interviews indicated that removing work-related stress factors such as not having a toilet nearby resulted in employees feeling much more at ease. For most patients, this led to lower absenteeism, higher work ability, and lower costs for employers and society. The project was viewed positively by employees and employers alike. More openness was created between both parties and the taboo on the disease was lifted, which had an overall positive impact on patients' work-life balance.

Discussion This pilot project showed that teleworking and flexible working hours improved professional activity among IBD patients. The results could be used to inspire policy-makers and employers to give maximum support to chronically ill people eager to work.
464 COST-EFFECTIVENESS OF A MULTIMEDIA CAMPAIGN TO IMPROVE COPING WITH NON-SPECIFIC LOW BACK PAIN

${ }^{1}$ Arnela Suman, ${ }^{1}$ Frederieke G Schaafsma*, ${ }^{2}$ Rachelle Buchbinder, ${ }^{3}$ Maurits W van Tulder, ${ }^{1}$ Johannes R Anema. 'Dept. of Public and Occupational Health, VU University Medical Centre, Amsterdam Public Health research institute, The Netherlands; ${ }^{2}$ Monash Dept. of Clinical Epidemiology, Monash University, Melbourne, Australia; ${ }^{3}$ Dept. of Health Sciences, VU University Amsterdam, Amsterdam Public Health research institute, Netherlands

\subsection{6/oemed-2018-ICOHabstracts. 1550}

Introduction Specific low back problems are a common and costly problem in Western societies. The vast majority $(88 \%)$ of these costs are caused by indirect costs, including job absenteeism, productivity losses, and disability. To reduce these costs, a multimedia campaign was developed for patients with low back pain. This campaign aimed to improve patient cognitions and knowledge regarding back pain, and stimulated active coping including continuing work.

Methods We recruited patients via general practitioners and physiotherapists, and used a RCT design for evaluation. We compared the multimedia campaign to usual care. The campaign consisted of an interactive website, video films, social media and monthly newsletters. Social media included Facebook, Twitter and a patient forum. During the follow-up period of one year cognitions, knowledge, quality of life, absenteeism, and direct and indirect costs were measured and analysed for all patients.

Results 779 patients with low back pain participated, of which 448 patients in the control group and 331 patients in the intervention group. The average age was 56 years, and most patients were women, with a high level of education and a Dutch nationality. In the control group, 232 participants had a paid job, of which 121 reported a physically demanding job. In the intervention group, 183 participants had a paid job, of which 88 reported a physically demanding job. The campaign had no effect on cognitions. The campaign was cost-effective for quality of life, but not for back pain cognitions. The costs for loss of productivity at work were higher in the control group than intervention group, resulting in a potential saving of $€ 748$ per person.

Discussion This multimedia campaign was not effective in improving cognitions in patients with low back pain, but could lead to a reduction in absenteeism costs. From a societal perspective, the campaign was cost-saving.

\section{COLLABORATIVE FACTORS ASSOCIATED WITH POSITIVE ECONOMIC OUTCOMES IN WORK DISABILITY MANAGEMENT - A MULTIPLE CASE STUDY WITH MIXED METHODS}

T Leino*, I Pehkonen, J Turunen, P Juvonen-Posti. Finnish Institute of Occupational Health, Helsinki, Finland

\subsection{6/oemed-2018-ICOHabstracts. 1551}

Introduction Cost of lost labour input in Finland exceed 24 billion $€$ per year. The aim of the study was to find out the content and processes of work ability management and the factors that make it productive. Information of a 20 financial units from Finnish companies employing 600-11 500 were collected from the period 2008 to 2013. 
Methods The data on personnel, business activities, investments in work disability prevention and the costs of work disability were obtained from the companies and their occupational health care. The practices, structures, resources, and processes of work ability management, as well as internal and external co-operation were investigated through questionnaires and group interviews of the top management, HRM, supervisors, and employee representatives. We used the case descriptions, the complete mixed method data sets as a basis of the qualitative comparative analysis.

Results The companies increased investments into work disability prevention during follow-up by about $0.25 \%-1.5 \%$ of the payroll. Work disability costs per person-year decreased in about half of the participating companies and their units. In relation to payroll, the change in work disability costs in the studied organisations was $-2 \%$ to $1.5 \%$. From 2009 to 2013, and from 2010 to 2013, five and nine companies, respectively obtained a net benefit from their investments into work disability prevention. The reasons for the reduction in work disability costs were:

- the dismantling of barriers to co-operation,

- the visibility in practice of the strategic goals of work ability management,

- the way in which the work disability management measures focused on the main work disability risks, and

- the facilitation of multi-actor co-operation through coordination and the flow of information.

Discussion Companies that succeeded in managing changes and in maintaining the structures, activities and co-operation of these operations received more net benefits than those whose management of operations was disturbed by, for example, operational restructuring, or a significant person leaving HRM, the occupational safety organisation or occupational health services.

\section{EMPLOYER ACCOMMODATIONS AND PRODUCTIVITY LOSS FOR LONG-TERM SICK-LISTED WORKERS BEFORE, DURING AND AFTER SICK-LEAVE}

${ }^{1}$ Kerstin Ekberg* ${ }^{2}{ }^{2}$ Lars Bernfort, ${ }^{2}$ Jan Persson. ${ }^{1}$ Department of Medical and Health Sciences, Work and Rehabilitation, Linköping University, Sweden; ${ }^{2}$ Department of Medical and Health Sciences, Division of Health Care Analysis, Linköping University, Sweden

\subsection{6/oemed-2018-ICOHabstracts. 1552}

Introduction The study aimed to explore which interventions were performed by employers for sick-listed workers, employer costs for these measures, and if sickness presenteeism before and after the sick-leave period created costs for the employer.

Methods A web-questionnaire was sent to 393 supervisors of sick-listed workers ( $>30$ days) due to common mental disorders or musculoskeletal disorders randomly drawn from the national AFA Insurance registers. The questionnaire comprised questions about work tasks, accommodations and interventions to facilitate RTW, and estimated costs for these measures. Presenteeism was measured by questions on duration and degree of reduced work performance before and after sick-leave. Lost productivity during sick-leave was based on a question regarding performance of replacements. Accommodations were grouped using factor analysis. Statistical analyses were performed with multiple logistic regression analysis.

Results Response rate was 50\% $(n=198)$. The most common interventions by supervisors were contacts with other stakeholders, most often HR, occupational health care, and/or Social Insurance Office. Changed work tasks were the most common interventions at the workplace and psychotherapy was the most common individual intervention. Supervisors had difficulties in estimating costs for these interventions. In multiple logistic regression analysis contacts with other stakeholders increased time to RTW $(\mathrm{OR}=0.68, \mathrm{p}<0.02)$, changed or increased staffing reduced time to RTW $(O R=1.43, p<0.05)$, as did ergonomic interventions $(\mathrm{OR}=1.74, \mathrm{p}<0.004)$, and work task adjustments $(\mathrm{OR}=1.41, \mathrm{p}<0.07)$. Demographic factors were not associated with time until RTW. Employer costs for productivity loss before, during and after sick-leave were on average 10000 EUR.

Discussion Workplace interventions reduce time to RTW, while supervisory contacts with other stakeholders are associated with prolonged sick-leave. Costs due to presenteeism before and after RTW highlights the need for increased attention to preventive measures at the workplace before sick-leave, as well as for support during re-integration after RTW, to reduce productivity loss.

\section{DEVELOPMENT AND PILOT TESTING OF A TRIAGE TOOL FOR SICKNESS ABSENCE COUNSELLING OF SICK-LISTED WORKERS WITHOUT AN EMPLOYMENT CONTRACT}

HJ van Rijssen*, JR Kim, M Roerdinkholder. Dutch Institute of Employee Benefit Schemes (UWV), Amsterdam, The Netherlands

\subsection{6/oemed-2018-ICOHabstracts. 1553}

Introduction Sick-listed workers without a (relative) permanent employment relationship, e.g. temporary agency workers and unemployed workers, are at higher risk for prolonged work disability compared to sick-listed employees. It is therefore important to start sickness absence counselling as early as possible. Triage - the process of prioritising patients on the base of the urgency of need for care - may facilitate this. The aim of this study was to develop and pilot test a triage tool to identify quickly the necessary intensity of counselling by het Social Security Agency (SSA) for sick-listed workers without an employment contract.

Methods Literature review, interviews and expert opinions were used to develop an initial triage tool. The developed tool consisted of a digital self-reported questionnaire for the worker and a (programmed) set of decision rules. Workers without an employment contract who were sick-listed between November 2016 and May 2017 at two locations of the Dutch SSA were requested to complete the questionnaire. Usability of the triage tool was evaluated by means of four group interviews with the occupational health care professionals of the SSA (e.g. sickness absence counsellors, insurance physicians).

Results The triage tool incorporated the workers perspective regarding the period of sickness absence, health status, their disability and several other risk factors. Approximately 5.300 sick-listed workers completed the questionnaire. The sickness 